\title{
Structural, optical, opto-thermal and thermal properties of ZnS-PVA nanofluids synthesized through a radiolytic approach
}

\author{
Alireza Kharazmi ${ }^{*} 1,2$, Nastaran Faraji ${ }^{3}$, Roslina Mat Hussin ${ }^{1}$, Elias Saion ${ }^{1}$, \\ W. Mahmood Mat Yunus ${ }^{1}$ and Kasra Behzad ${ }^{4}$
}

\author{
Full Research Paper \\ Address: \\ 1Department of Physics, Faculty of Science, University Putra \\ Malaysia, Serdang 43400, Selangor, Malaysia, ${ }^{2}$ School of Chemistry, \\ University of New South Wales, Sydney, NSW 2052, Australia, \\ ${ }^{3}$ School of Materials Science and Engineering, University of New \\ South Wales, Sydney, NSW 2052, Australia and ${ }^{4}$ Department of \\ Physics, Science Faculty, Shahr-e-Qods Branch, Islamic Azad \\ University, Tehran, Iran \\ Email: \\ Alireza Kharazmi* - kharazmi.alireza@hotmail.com \\ * Corresponding author \\ Keywords: \\ Fourier transform infrared spectroscopy (FTIR); specific heat; thermal \\ conductivity; thermal effusivity; ZnS nanoparticles
}

Beilstein J. Nanotechnol. 2015, 6, 529-536. doi:10.3762/bjnano.6.55

Received: 01 June 2014

Accepted: 26 January 2015

Published: 23 February 2015

Associate Editor: J. J. Schneider

(c) 2015 Kharazmi et al; licensee Beilstein-Institut. License and terms: see end of document.

\begin{abstract}
This work describes a fast, clean and low-cost approach to synthesize ZnS-PVA nanofluids consisting of ZnS nanoparticles homogeneously distributed in a PVA solution. The ZnS nanoparticles were formed by the electrostatic force between zinc and sulfur ions induced by gamma irradiation at a dose range from 10 to $50 \mathrm{kGy}$. Several experimental characterizations were conducted to investigate the physical and chemical properties of the samples. Fourier transform infrared spectroscopy (FTIR) was used to determine the chemical structure and bonding conditions of the final products, transmission electron microscopy (TEM) for determining the shape morphology and average particle size, powder X-ray diffraction (XRD) for confirming the formation and crystalline structure of $\mathrm{ZnS}$ nanoparticles, UV-visible spectroscopy for measuring the electronic absorption characteristics, transient hot wire (THW) and photoacoustic measurements for measuring the thermal conductivity and thermal effusivity of the samples, from which, for the first time, the values of specific heat and thermal diffusivity of the samples were then calculated.
\end{abstract}

\section{Introduction}

Over the past decade, the unique properties of nanometer-scale semiconductors have been investigated in the field of synthesis and characterization. Among the II-VI compounds, $\mathrm{ZnS}$ as a direct wide band-gap semiconductor $\left(E_{\mathrm{g}} \approx 3.6 \mathrm{eV}\right)$ [1], has gained more attention due to its potential applications in optoelectronics [2], lasers [3] and solar cells [4]. 
During the fabrication of devices that utilize semiconductor nanoparticles (NPs), such as ZnS NPs, the tendency of particles to agglomerate needs to be taken into consideration. The use of organic polymers as a host can help to prevent agglomeration and mobilization of the semiconductor nanoparticles [5]. Moreover, the incorporation of inorganic and organic materials enhances and combines the properties of both phases in the final product [6]. Poly(vinyl alcohol) (PVA) is one of the most suitable polymers [7] and has been reported in numerous publications to be a good choice for preparing colloidal suspensions due to its significant advantageous such as processability and high transmittance [8]. Various physical and chemical routes have been used to synthesize these nanocomposites such as microwave irradiation [9], chemical synthesis [10], sputtering [11], sol-gel [12], solid state synthesis [13] and gamma irradiation [14]. Among these methods, gamma irradiation has been considerably employed in various works because it can be applied under ambient conditions and at room temperature. In addition, this method provides size control and avoids impurities originating from chemical initiators [6].

The interest in measuring the thermal conductivity $(k)$ and the thermal effusivity $(e)$ of nanofluids containing semiconductors has increased [15] because of their increasing use in devices [16]. The photoacoustic (PA) effect has been demonstrated to be a valid technique for these measurements. It has the advantage of being a non-radiative de-excitation process following the absorption of light [17,18]. The aforementioned methods consequently provide the possibility for calculating specific heat $\left(C_{\mathrm{p}}\right)$ and thermal diffusivity $(\alpha)$.

In this work, structural, optical, opto-thermal and thermal properties of ZnS-PVA nanofluids synthesized through a room temperature radiolytic method were studied, since these properties are considerable factors in optoelectronic devices. To the best of our knowledge, this is the first report on thermal characteristics of ZnS-PVA nanofluids in which thermal diffusivity and specific heat of nanofluids were calculated by using formerly known values of thermal conductivity and effusivity, which were acquired by using transient hot wire (THW) and photoacoustic methods.

\section{Results and Discussion}

According to [19], the interaction of gamma radiation with the aqueous solution generates aqueous electrons $\left(\mathrm{e}^{-}\right.$free $)$that reduce $\mathrm{S}_{2} \mathrm{O}_{3}{ }^{2-}$ to $\mathrm{S}^{2-}$. Zinc ions $\left(\mathrm{Zn}^{2+}\right)$ are already present in the solution and through the combination of sulfur and zinc ions $\mathrm{ZnS}$ nuclei are formed, which agglomerate into ZnS NPs. The mechanism of this reaction is as follows:

$$
\begin{gathered}
\mathrm{H}_{2} \mathrm{O} \stackrel{\gamma \text {-rays }}{\longrightarrow} \mathrm{e}_{\text {free }}^{-}, \mathrm{H}^{+}, \mathrm{H}_{3} \mathrm{O}^{-}, \mathrm{H}^{\bullet}, \mathrm{OH}^{\bullet}, \mathrm{H}_{2}, \mathrm{H}_{2} \mathrm{O}_{2} \\
\mathrm{~S}_{2} \mathrm{O}_{3}{ }^{2-}+\mathrm{e}_{\text {free }}^{-} \rightarrow \mathrm{S}^{-}+\mathrm{SO}_{3}^{2-}
\end{gathered}
$$

Thiosulfate ions $\left(\mathrm{S}_{2} \mathrm{O}_{3}{ }^{2-}\right)$ were obtained by dissolving sodium thiosulfate $\left(\mathrm{NaS}_{2} \mathrm{O}_{3}\right)$ in the PVA solution.

$$
\begin{gathered}
\mathrm{S}^{-}+\mathrm{e}_{\text {free }}^{-} \rightarrow \mathrm{S}^{2-} \\
\mathrm{Zn}^{2+}+\mathrm{S}^{2-} \rightarrow \mathrm{ZnS} \\
\mathrm{ZnS}+\mathrm{ZnS} \rightarrow[\mathrm{ZnS}]_{2} \\
\mathrm{ZnS}+\mathrm{ZnS}_{n} \rightarrow[\mathrm{ZnS}]_{n+1}
\end{gathered}
$$

Equation 5 and Equation 6 indicate the agglomeration of $\mathrm{ZnS}$ NPs. The PVA matrix limits this agglomeration and leads to a smaller NP size.

The first noticeable hint to the formation of $\mathrm{ZnS}$ is the change of color of the samples from transparent to white. It was also observed that the viscosity of the final product was increased by increasing the dose from 10 to $50 \mathrm{kGy}$. This increment is due to the residual amount of acetate, which will be discussed later.

Figure 1 depicts the FTIR spectra of PVA and the PVA-ZnS nanofluid. The main peaks of PVA were observed at 3280 , $2917,1690,1425,1324,1081$ and $839 \mathrm{~cm}^{-1}$. These peaks are assigned to the $\mathrm{O}-\mathrm{H}$ stretching vibration of the hydroxy group, $\mathrm{CH}_{2}$ asymmetric stretching vibration, $\mathrm{C}=\mathrm{O}$ carbonyl stretch,

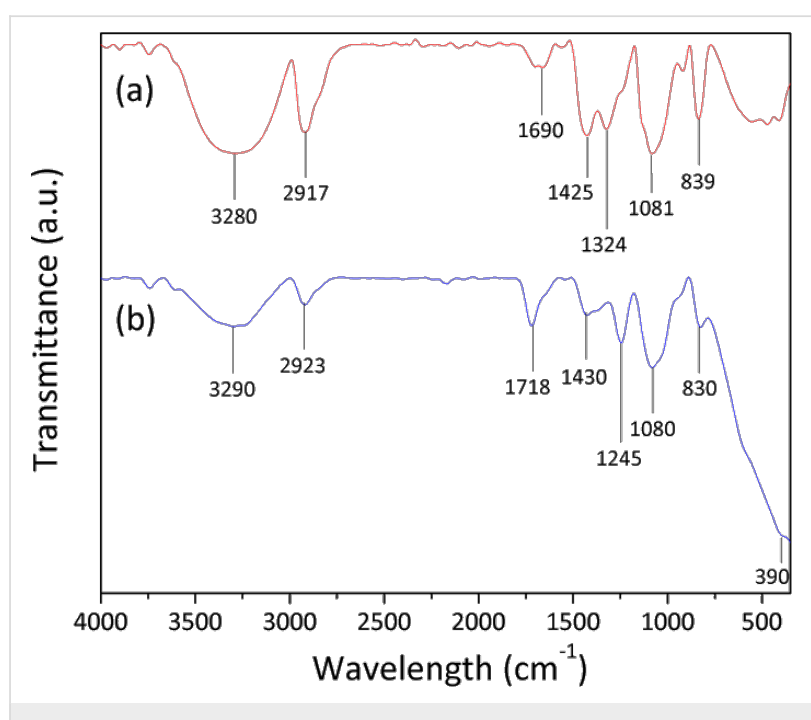

Figure 1: FTIR spectra of (a) PVA (b) PVA-ZnS. 
$\mathrm{C}-\mathrm{H}$ bending vibration of $\mathrm{CH}_{2}, \mathrm{C}-\mathrm{H}$ deformation vibration, $\mathrm{C}-\mathrm{O}$ stretching of acetyl groups and $\mathrm{C}-\mathrm{C}$ stretching vibration, accordingly [20-22]. Similar peaks were observed for the $\mathrm{ZnS}-\mathrm{PVA}$ nanofluid in addition to two new peaks located at 1245 and $390 \mathrm{~cm}^{-1}$ due to the $\mathrm{C}-\mathrm{H}$ wagging and $\mathrm{ZnS}$ NPs, respectively [22,23]. These results have been sorted in Table 1 .

According to [24], residual acetate can acetylate PVA, as illustrated in Figure 2. Indeed, a copolymer of vinyl alcohol and acetate is produced in a ratio of $m$ and $n \mathrm{~mol} \%$, in which $n$ is significantly smaller than $m$ due to the low concentration of residual acetate. Despite the low amount of acetate, the weight of the polymer chain is increased to some extent as a consequence of this process that results in poly(vinyl alcohol-co-vinyl acetate). Therefore, it can be envisaged that the viscosity is increased as well.

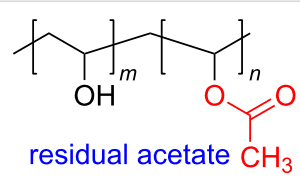

Figure 2: Illustration of hydrolyzed PVA.

Generally, the vibrational spectra of PVA exhibits the characteristics of the vinyl alcohol monomer and it is expected to reveal 17 modes of vibrations [22]. The $\mathrm{C}-\mathrm{H}$ wagging mode is expected to appear at about $1240 \mathrm{~cm}^{-1}$ for PVA. In this experiment, the $\mathrm{C}-\mathrm{H}$ wagging mode appeared only after the acetylation process, which can be explained by a structure deformation of the PVA backbone. Another expected vibrational mode for PVA is the vibration mode of carbonyl stretching at about $1700 \mathrm{~cm}^{-1}$. The carbonyl stretching vibration was observed at $1690 \mathrm{~cm}^{-1}$ and $1718 \mathrm{~cm}^{-1}$ for PVA and ZnS-PVA nanofluid, respectively. The intensity of the carbonyl stretching mode was increased in the ZnS-PVA nanofluid, which suggests the presence of more carbonyl sites. The reason for this is the interaction of gamma radiation with the aqueous solution that caused the breaking of $-\mathrm{H}$ and $-\mathrm{OH}$ bonds, and therefore the formation of more carbonyl double bonds $(\mathrm{C}=\mathrm{O})$ [20]. Consequently, the intensity of peak corresponding to the carbonyl stretching vibration was increased and shifted toward higher wavelengths from 1690 to $1718 \mathrm{~cm}^{-1}$. Despite the acetylation of PVA moieties, the chain structure of PVA is, in general, breaking upon increasing the dose due to the bond scission because of the high energy of irradiation [20].

Figure 3 shows the TEM images of ZnS NPs after irradiation with doses of 10, 30 and $50 \mathrm{kGy}$, respectively. The ZnS NPs are spherical and exhibit a homogeneous distribution, especially at higher radiation doses. The average sizes of the ZnS NPS were found to be 53,57 and $59 \mathrm{~nm}$ for samples irradiated with doses

\begin{tabular}{|c|c|c|c|}
\hline assignment & observed wavelength for PVA $\left(\mathrm{cm}^{-1}\right)$ & observed wavelength for ZnS-PVA $\left(\mathrm{cm}^{-1}\right)$ & reference \\
\hline $\mathrm{OH}$ stretching & 3280 & 3290 & {$[20,21]$} \\
\hline $\mathrm{CH}_{2}$ asymmetric stretching & 2917 & 2923 & {$[20,21]$} \\
\hline $\mathrm{C}=\mathrm{O}$ carbonyl stretching & 1690 & 1718 & [20-22] \\
\hline $\mathrm{CH}_{2}$ bending & 1425 & 1430 & {$[20,21]$} \\
\hline $\mathrm{C}-\mathrm{H}$ deformation & 1324 & - & {$[20,21]$} \\
\hline $\mathrm{C}-\mathrm{H}$ wagging & - & 1245 & {$[22,23]$} \\
\hline C-O stretching & 1081 & 1080 & {$[20,21]$} \\
\hline $\mathrm{C}-\mathrm{C}$ stretching & 839 & 830 & {$[20,21]$} \\
\hline ZnS NPs & - & 390 & [23] \\
\hline
\end{tabular}

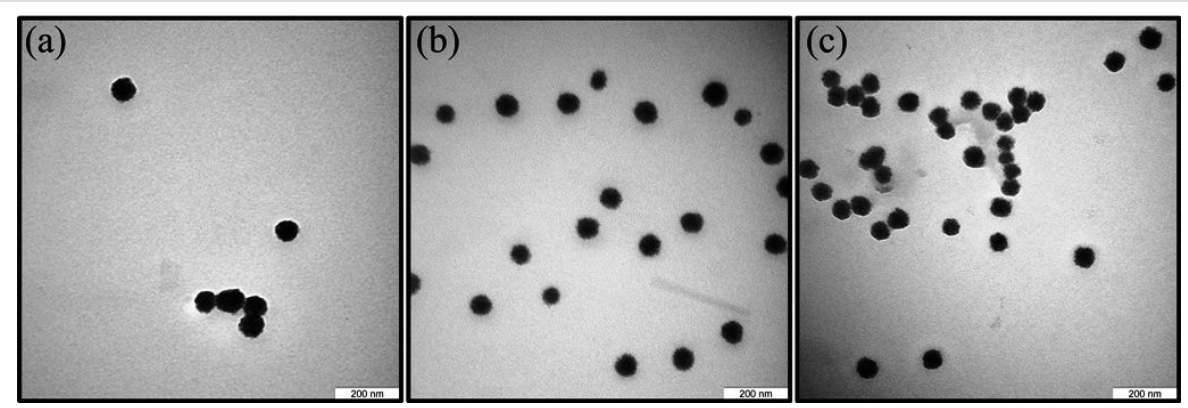

Figure 3: TEM images of ZnS NPs within PVA matrix at (a) $10 \mathrm{kGy}$, (b) $30 \mathrm{kGy}$ and (c) $50 \mathrm{kGy}$ dose. 
of 10, 30 and $50 \mathrm{kGy}$, respectively. An increase of particle size with increasing dose in this study indicated that when more metal ions present in the sample the increased number of sulfur ions induced by gamma radiation agglomerated more $\mathrm{ZnS}$ units to enlarge the particle size at higher doses. Moreover, the number of ZnS NPs was increased when increasing the dose from 10 to $50 \mathrm{kGy}$ because more $\mathrm{ZnS}$ NPs were formed due to an increasing number of non-metal ions in the solution. This increment in number supports the enhancement of some related phenomena such as intensity of absorption which will be later discussed.

Figure 4 shows the XRD pattern of $\mathrm{ZnS}-\mathrm{PVA}$ nanofluid samples synthesized with 10 to $50 \mathrm{kGy}$ doses showing the structural characteristic and formation of $\mathrm{ZnS}$ NPs. The main observed peak at $19.5^{\circ}$ is related to PVA in the solution [25]. The observed peaks at $2 \theta$ values of $28.13^{\circ}, 47.69^{\circ}$ and $57.42^{\circ}$ were assigned to the (111), (220) and (311) lattice plane spacings of cubic ZnS, (zinc blende, ICDD PDF 00-065-0309) with a lattice parameter of $5.4 \AA$ and $157.46 \AA^{3}$ cell volume.

The absorption spectra of ZnS-PVA nanofluid samples are depicted in Figure 5. The absorption in the wavelength range of 310 to $320 \mathrm{~nm}$ varies for irradiated samples from 10 to $50 \mathrm{kGy}$ doses. Consequently, a slight blue shift occurred compared to the absorption maximum (340 nm) of bulk $\mathrm{ZnS}$ [26]. Additionally, the result indicated an enhancement in the intensity of the absorption spectra for irradiated samples at higher doses due to the higher number of ZnS NPs. The peak located at $260 \mathrm{~nm}$ is due to the formation of some chromophores as a consequence of carbonyl formation in the PVA structure upon irradiation [20]. The intensity of this peak increases, which indicates an increase of the carbonyl concentration in agreement with the FTIR results.

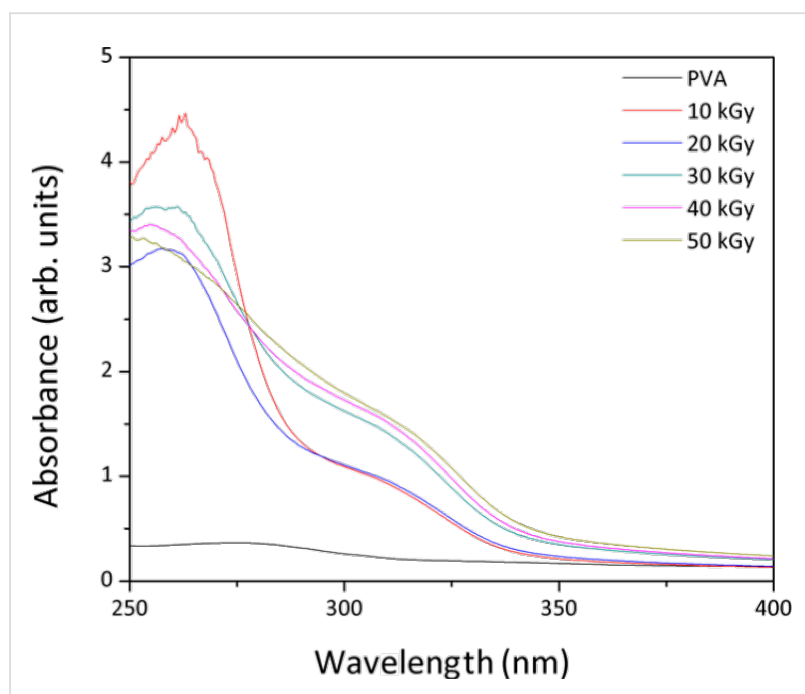

Figure 5: Optical spectra of ZnS-PVA nanofluids synthesized at various doses.

The optical band gap energy of the ZnS NPs was estimated through the Tauc equation as follows [6]:

$$
(\alpha h v)^{1 / n}=B\left(h v-E_{\mathrm{g}}\right)
$$

where $\alpha$ is the absorption coefficient, $h v$ is the photon energy of the incident light, $E_{\mathrm{g}}$ is the band gap energy, $B$ is a constant and $n$ depends on the type of transition and is $1 / 2,1,3 / 2$ and 2 for allowed direct, allowed indirect, forbidden direct and forbidden

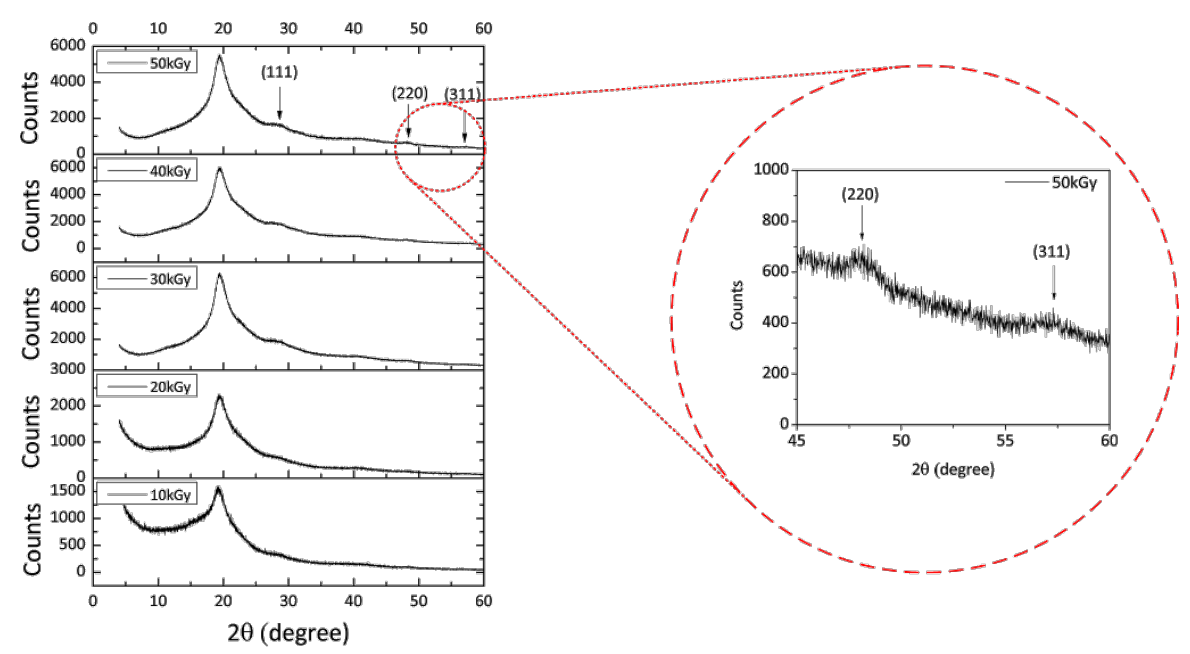

Figure 4: XRD pattern of ZnS NPs mediated by PVA from 10 to $50 \mathrm{kGy}$ doses. 
indirect, respectively. The absorption band gap of ZnS NPs was estimated by extrapolating the linear portion of $(\alpha h v)^{2}$ as a function of $h v$. Consequently, the intercept of the extrapolated line with the $\mathrm{x}$-axis, indicates the band gap energy of the ZnS NPs, as shown in Figure 6.

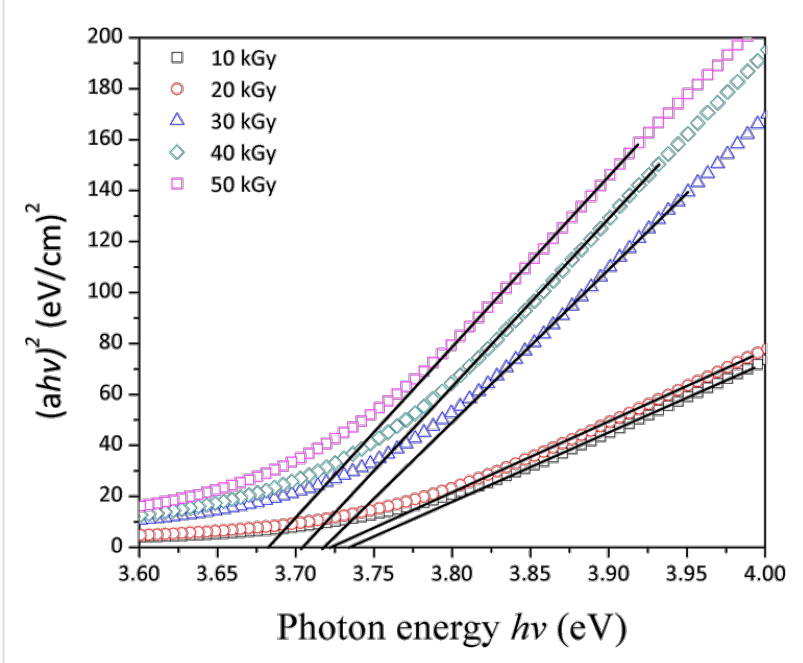

Figure 6: Optical band gap energy of ZnS NPs after irradiation with doses of 10 to $50 \mathrm{kGy}$.

The absorption coefficient ( $\alpha$ ) was calculated by $\alpha=2.303 \mathrm{~A} / \mathrm{d}$ where $A$ is the absorbance and $d$ is the thickness of the sample [27]. The band gap of ZnS NPs decreased from 3.74 to $3.68 \mathrm{eV}$ with increasing dose from 10 to $50 \mathrm{kGy}$ due to increasing particles size; however, these values are generally higher than the band gap energy of bulk $\mathrm{ZnS} 3.6 \mathrm{eV}$ [1]. The band gap energy implies a very weak quantum confinement effect. Since the wave functions of electrons and holes are still overlapped, the movement of the excitons instigates a weak confinement [28].

The thermal conductivity of distilled water, PVA and $\mathrm{ZnS}$ nanofluids were measured and are listed in Table 2. The thermal conductivity of distilled water was measured to calibrate the set-up and agreed well with the reported value of the literature [29]. The thermal conductivity of the nanofluid was found to have a higher value than that of PVA due to the Brownian motion, convection, and heat diffusion in the presence of $\mathrm{ZnS}$ NPs [14]. The thermal conductivity of ZnS-PVA nanofluids decreases from lower to higher irradiation doses, as shown in Figure 7a. This decrement is explained by means of modification and breakdown in the chain structure of PVA upon gamma irradiation, as previously explained by FTIR results.

According to [30], the principle of heat transport is explained by phonons where $k$ can be written as follows [31]:

$$
k=\frac{1}{3} \rho C_{\mathrm{p}} \cup l
$$

where $\rho$ is the density, $C_{\mathrm{p}}$ is the specific heat at constant pressure, $v$ is the phonon velocity and $l$ is the phonon mean free path. Therefore, changes in the phonon mean free path proportionally change the thermal conductivity.

Figure 8 shows the typical PA signal as a function of frequency for (a) distilled water and ethylene glycol and (b) ZnS-PVA at $50 \mathrm{kGy}$. In order to calibrate the set-up, the thermal effusivity of distilled water and ethylene glycol were measured and found to be 0.160 and $0.082\left(\mathrm{~W} \cdot \mathrm{s}^{1 / 2} \cdot \mathrm{cm}^{-2} \cdot \mathrm{K}^{-1}\right)$, which perfectly agreed with the reported values of the literature [32-34]. The thermal effusivity of distilled water, PVA and ZnS-PVA nanofluids are given in Table 2. The value of thermal effusivity decreased upon the increase of the radiation dose, as illustrated in Figure $7 \mathrm{~b}$. The decrement of thermal effusivity can be also explained by a decreasing chain length of PVA and, consequently, a shorter phonon mean free path due to the bond scission of PVA upon irradiation.

The $C_{\mathrm{p}}$ and $\alpha$ values of distilled water, PVA and ZnS-PVA nanofluids were then calculated through the relationships of $C_{\mathrm{p}}$, $\alpha, e$ and $k[35]$ :

\begin{tabular}{|c|c|c|c|c|}
\hline sample & $\begin{array}{l}k \\
\left(\mathrm{~W} \cdot \mathrm{cm}^{-1} \cdot \mathrm{K}^{-1}\right) \times 10^{-2}\end{array}$ & $\begin{array}{l}e \\
\left(\mathrm{~W} \cdot \mathrm{s}^{1 / 2} \cdot \mathrm{cm}^{-2} \cdot \mathrm{K}^{-1}\right)\end{array}$ & $\begin{array}{l}\alpha \\
\left(\mathrm{cm}^{2} \cdot \mathrm{s}^{-1}\right)\end{array}$ & $\begin{array}{l}C_{p} \\
\left(J \cdot g^{-1} \cdot K^{-1}\right)\end{array}$ \\
\hline distilled water & 0.614 & 0.160 & 0.147 & 4.169 \\
\hline PVA solution & 0.551 & 0.111 & 0.246 & 2.129 \\
\hline ZnS-PVA 10 kGy & 0.561 & 0.151 & 0.138 & 3.870 \\
\hline ZnS-PVA 20 kGy & 0.558 & 0.139 & 0.161 & 3.297 \\
\hline ZnS-PVA 30 kGy & 0.557 & 0.135 & 0.170 & 3.116 \\
\hline ZnS-PVA 40 kGy & 0.556 & 0.130 & 0.183 & 2.894 \\
\hline ZnS-PVA 50 kGy & 0.554 & 0.123 & 0.203 & 2.600 \\
\hline
\end{tabular}



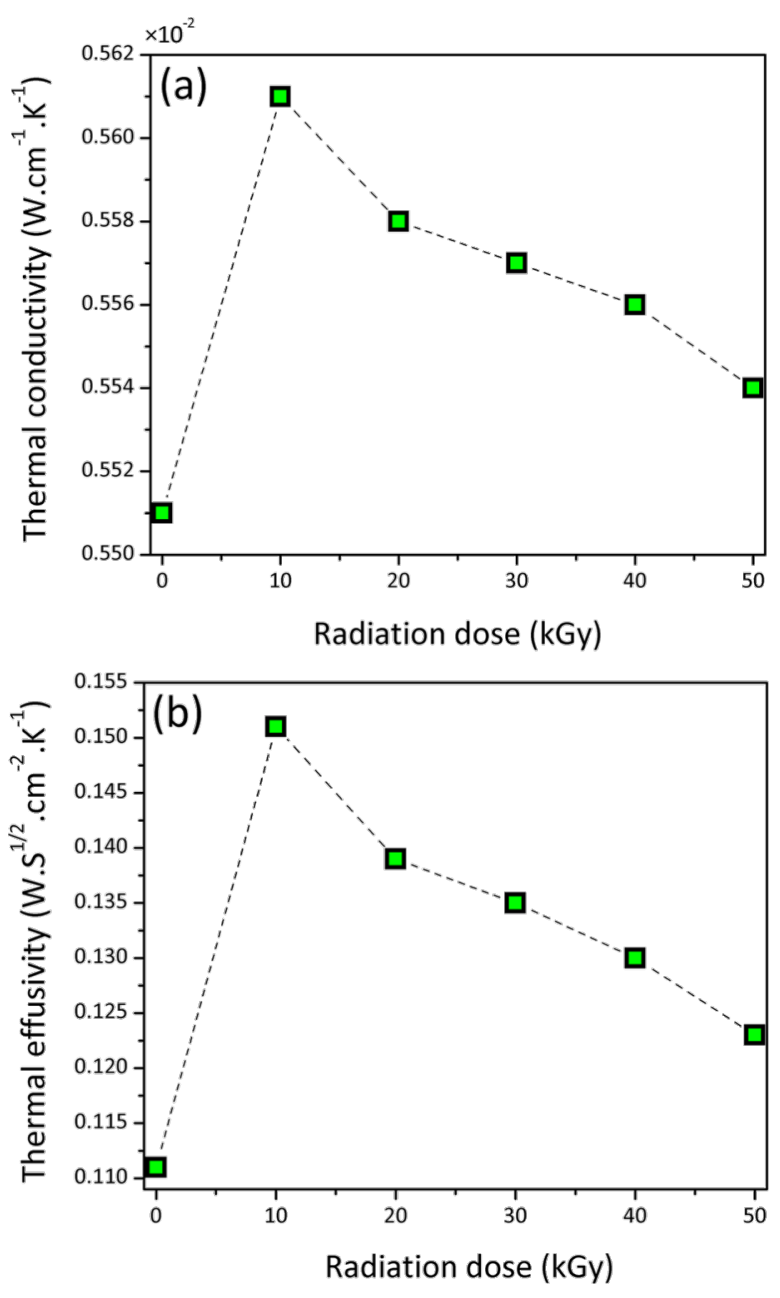

Figure 7: Trend of (a) thermal conductivity and (b) thermal effusivity of the PVA solution ( $0 \mathrm{kGy}$ ) and $\mathrm{ZnS}$ nanofluids as a function of the radiation dose.

$$
\begin{gathered}
e=\sqrt{k \rho C_{\mathrm{p}}}, \\
\alpha=\frac{k}{\rho C_{\mathrm{p}}} .
\end{gathered}
$$

In order to measure the value of $C_{\mathrm{p}}$ and $\alpha$, the mass of a given volume of each sample $(35 \mathrm{~mL})$ was determined, and so the density of the samples calculated. The calculated density of distilled water and the samples were found to be 1.00 and $1.05 \mathrm{~g} \cdot \mathrm{cm}^{-3}$, respectively. The $C_{\mathrm{p}}$ of samples was then calculated through Equation 9 by using formerly known values of $e$, $k$ and $\rho$. Finally, Equation 10 was applied to calculate the value of $\alpha$. The calculated values of $C_{\mathrm{p}}$ and $\alpha$ are also listed in Table 2. It was found that, in contrast to the values of $k, e$ and
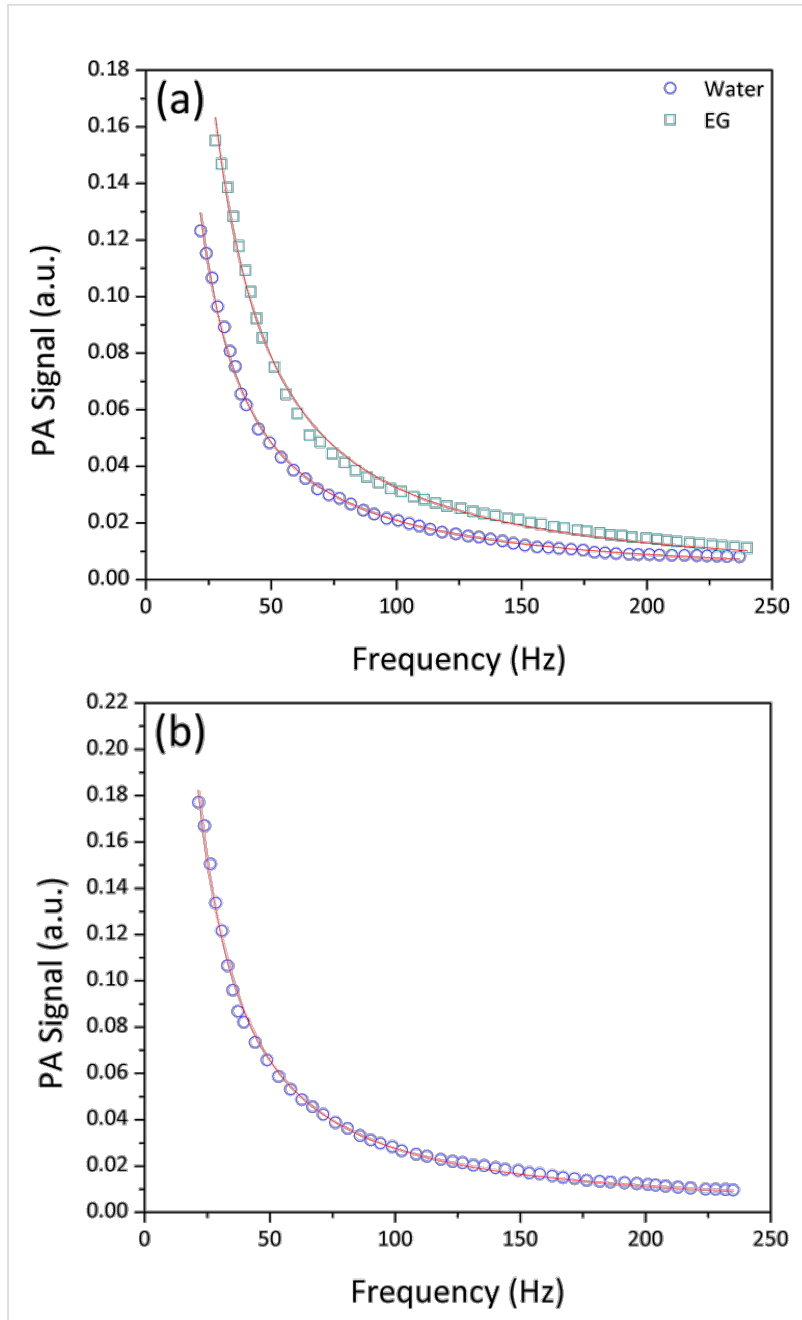

Figure 8: A typical PA signal as a modulation of frequency for (a) water and ethylene glycol, (b) ZnS-PVA nanofluids after irradiation with $50 \mathrm{kGy}$. The solid curve and hollow symbols indicate the theoretical fitting and experimental data, respectively.

$C_{\mathrm{p}}, \alpha$ increases with the irradiation dose, because it is inversely proportional to $C_{\mathrm{p}}$.

\section{Conclusion}

The ZnS-PVA nanofluids were successfully synthesized by using gamma irradiation. The PVA was acetylated by residual acetate from the zinc acetate source, which leads to a higher viscosity of the samples. In addition, the chain structure of PVA was modified as a consequence of the high energy of gamma irradiation. The average size of the spherical $\mathrm{ZnS}$ NPs was found to increase from 53 to $59 \mathrm{~nm}$ with increasing doses from 10 to $50 \mathrm{kGy}$. The ZnS NPs exhibit zinc blende structure with the crystal lattice parameter of $5.4 \AA$ and a cell volume of $157.46 \AA^{3}$. The electronic absorption spectra revealed two absorption peaks located at 310 and $260 \mathrm{~nm}$ due to the ZnS NPs and carbonyl groups in the PVA structure, respectively. The 
band gap of ZnS NPs varied from 3.74 to $3.68 \mathrm{eV}$ from lower to higher irradiation doses, which hints to a weak quantum confinement. Thermal conductivity and effusivity of the samples exhibited an increment upon the irradiation due to the chain scission of PVA. In contrast, the calculated value of thermal diffusivity was increased due to the decrement of specific heat since these two parameters are inversely proportional.

\section{Experimental}

In this work, ZnS-PVA nanofluids were prepared by a room temperature radiolytic method using ${ }^{60} \mathrm{Co}$ gamma irradiation. In a typical procedure, five different aqueous solutions of PVA $(5 \mathrm{wt} \%)$ were prepared in a water bath for $1 \mathrm{~h}$ at $75^{\circ} \mathrm{C}$. Subsequently, the same amount, $10^{-2}$ molar ratio with respect to water, of $\mathrm{Zn}\left(\mathrm{CH}_{3} \mathrm{COO}\right)_{2}$ and $\mathrm{Na}_{2} \mathrm{~S}_{2} \mathrm{O}_{3}$ were added and the solution was stirred for $2 \mathrm{~h}$. The solutions were finally irradiated with doses from 10 to $50 \mathrm{kGy}$.

The chemical structure of samples were investigated by Fourier transform infrared spectroscopy (Perkin Elmer model 1650), the morphology of samples was observed by transmission electron microscopy (JOEL 2010F UHR) operated at $200 \mathrm{kV}$, the structure of the final products was confirmed by powder X-ray diffraction in the $2 \theta$ range of 4 to $60^{\circ}$ by using Philips X-ray diffractometer (7602 EA Almelo) with $\mathrm{Cu} \mathrm{K} \alpha$ radiation $(\lambda=0.1542 \mathrm{~nm})$. Optical absorption spectra were recorded by using a UV-vis spectrometer (Shimadzu-UV1650PC) in the wavelength range of 250 to $400 \mathrm{~nm}$. The thermal conductivity and thermal effusivity of the samples were measured by transient hot wire (THW) and photoacoustic technique, respectively.

The thermal conductivity of the ZnS-PVA nanocomposites was measured by a Decagon devices KD2 Thermal analyzer where the transient line heat source is used to determine the thermal response. This device has $5 \%$ accuracy over the 5 to $40{ }^{\circ} \mathrm{C}$ temperature range. The device basically contains a singleneedle sensor attached to a handheld readout unit. The sensor works as both heat source and thermometer. Technically, a single run experiment took $2 \mathrm{~min}$. For the first 30 seconds, the probe was heated by a known current, and subsequently the device continued running for another $1.5 \mathrm{~min}$ to provide a steady temperature. The probe is also equipped with a thermistor that can detect and store the changes in temperature. Finally, the thermal conductivity was computed by the temperature difference versus time.

The thermal effusivity of samples was measured by a photoacoustic technique based on Rosencwaig-Gersho theory [36]. The experimental and theoretical fitting of this method were comprehensively explained in our previous work [37].

\section{References}

1. Deng, Z.; Yan, H.; Liu, Y. Angew. Chem. 2010, 122, 8877-8880. doi:10.1002/ange.201003952

2. Ma, C.; Moore, D.; Li, J.; Wang, Z. L. Adv. Mater. 2003, 15, 228-231. doi:10.1002/adma.200390052

3. Falcony, C.; Garcia, M.; Ortiz, A.; Alonso, J. C. J. Appl. Phys. 1992, 72, 1525-1527. doi:10.1063/1.351720

4. Yamaguchi, T.; Yamamoto, Y.; Tanaka, T.; Yoshida, A. Thin Solid Films 1999, 343-344, 516-519. doi:10.1016/S0040-6090(98)01665-4

5. Cheng, X.; Zhao, Q.; Yang, Y.; Tjong, S. C.; Li, R. K. Y. J. Mater. Sci. 2010, 45, 777-782. doi:10.1007/s10853-009-4000-z

6. Kharazmi, A.; Saion, E.; Faraji, N.; Soltani, N.; Dehzangi, A. Chin. Phys. Lett. 2013, 30, 057803. doi:10.1088/0256-307X/30/5/057803

7. Mansur, H. S.; Mansur, A. A. P. Mater. Chem. Phys. 2011, 125, 709-717. doi:10.1016/j.matchemphys.2010.09.068

8. Khanna, P. K.; Singh, N.; Charan, S.; Subbarao, V. V. V. S.; Gokhale, R.; Mulik, U. P. Mater. Chem. Phys. 2005, 93, 117-121. doi:10.1016/j.matchemphys.2005.02.029

9. Hu, H.; Wang, X.; Liu, F.; Wang, J.; Xu, C. Synth. Met. 2011, 161, 404-410. doi:10.1016/j.synthmet.2010.12.018

10. Maity, R.; Chattopadhyay, K. K. Nanotechnology 2004, 15, 812. doi:10.1088/0957-4484/15/7/017

11. Mandal, S. K.; Chaudhuri, S.; Pal, A. K. Thin Solid Films 1999, 350 , 209-213. doi:10.1016/S0040-6090(99)00236-9

12. Bhattacharjee, B.; Ganguli, D.; Chaudhuri, S.; Pal, A. K. Mater. Chem. Phys. 2003, 78, 372-379. doi:10.1016/S0254-0584(02)00159-1

13. Lu, H.-Y.; Chu, S.-Y.; Tan, S.-S. J. Cryst. Growth 2004, 269, 385-391. doi:10.1016/j.jcrysgro.2004.05.050

14. Kharazmi, A.; Saion, E.; Faraji, N.; Hussin, R. M.; Yunus, W. M. M. Radiat. Phys. Chem. 2014, 97, 212-216. doi:10.1016/j.radphyschem.2013.12.003

15. Jiménez-Pérez, J. L.; Sánchez-Ramírez, J. F.; Cornejo-Monroy, D.; Gutierrez-Fuentes, R.; Pescador Rojas, J. A.; Cruz-Orea, A.; Algatti, M. A.; Jacinto, C. Int. J. Thermophys. 2012, 33, 69-79. doi:10.1007/s10765-011-1139-z

16. Ramachandran, E.; Raji, P.; Ramachandran, K.; Natarajan, S. Cryst. Res. Technol. 2006, 41, 64-67. doi:10.1002/crat.200410531

17. Gutiérrez-Juárez, G.; Zelaya-Angel, O.; Alvarado-Gil, J. J.; Vargas, H.; de O. Pastore, H.; Barone, J. S.; Hernandez-Velez, M.; Baños, L. J. Chem. Soc., Faraday Trans. 1992, 92, 2651-2657. doi:10.1039/ft9969202651

18. Hernández-Guevara, A.; Cruz-Orea, A.; Vigil, O.; Villavicencio, H.; Sánchez-Sinencio, F. Mater. Lett. 2000, 44, 330-335. doi:10.1016/S0167-577X(00)00054-9

19. Liu, W.; He, W.; Zhang, Z.; Zheng, C.; Li, J.; Jiang, H.; Ge, X.; Liu, H. J. Cryst. Growth 2006, 290, 592-596. doi:10.1016/j.jcrysgro.2005.12.097

20. Bhat, N. V.; Nate, M. M.; Kurup, M. B.; Bambole, V. A.; Sabharwal, S. Nucl. Instrum. Methods Phys. Res., Sect. B 2005, 237, 585-592. doi:10.1016/j.nimb.2005.04.058

21. Lee, J.; Isobe, T.; Senna, M. J. Colloid Interface Sci. 1996, 177, 490-494. doi:10.1006/jcis.1996.0062

22. Omkaram, I.; Chakradhar, R. P. S.; Rao, J. L. Physica B 2007, 388, 318-325. doi:10.1016/j.physb.2006.06.134

23. Elashmawi, I. S.; Hakeem, N. A.; Selim, M. S. Mater. Chem. Phys. 2009, 115, 132-135. doi:10.1016/j.matchemphys.2008.11.034 
24. Andrade, G. I.; Barbosa-Stancioli, E. F.; Piscitelli Mansur, A. P.; Vasconcelos, W. L.; Mansur, H. S. J. Mater. Sci. 2008, 43, 450-463. doi:10.1007/s10853-007-1953-7

25. Faraji, N.; Mat Younus, W. M.; Kharazmi, A.; Saion, E.; Shahmiri, M.; Tamchek, N. J. Eur. Opt. Soc. Rapid Publ. 2012, 7, 12040. doi:10.2971/jeos.2012.12040

26. Nanda, J.; Sapra, S.; Sarma, D. D.; Chandrasekharan, N.; Hodes, G. Chem. Mater. 2000, 12, 1018-1024. doi:10.1021/cm990583f

27. Murugan, A. V.; Kale, B. B.; Kulkarni, A. V.; Kunde, L. B.; Saaminathan, V. J. Mater. Sci.: Mater. Electron. 2005, 16, 295-299. doi:10.1007/s10854-005-0547-x

28. Shao, L.-X.; Chang, K.-H.; Hwang, H.-L. Appl. Surf. Sci. 2003, 212-213, 305-310. doi:10.1016/S0169-4332(03)00085-0

29. Beirão, S. G. S.; Ramires, M. L. V.; Dix, M.; Nieto de Castro, C. A. Int. J. Thermophys. 2006, 27, 1018-1041. doi:10.1007/s10765-006-0093-7

30. Choy, C. L.; Wong, S. P.; Young, K. J. Polym. Sci., Polym. Phys. Ed. 1985, 23, 1495-1504. doi:10.1002/pol.1985.180230803

31. Mergenthaler, D.; Pietralla, M.; Roy, S.; Kilian, H. G. Macromolecules 1992, 25, 3500-3502. doi:10.1021/ma00039a030

32. Balderas-Lopez, J. A.; Acosta-Avalos, D.; Alvarado, J. J.; Zelaya-Angel, O.; Sanchez-Sinencio, F.; Falcony, C.; Cruz-Orea, A.; Vargas, H. Meas. Sci. Technol. 1995, 6, 1163. doi:10.1088/0957-0233/6/8/011

33. Sikorska, A.; Linde, B. B. J.; Żwirbla, W. Chem. Phys. 2005, 320, 31-36. doi:10.1016/j.chemphys.2005.06.024

34. Balderas-López, J. A.; Mandelis, A. Int. J. Thermophys. 2003, 24 , 463-471. doi:10.1023/A:1022972021880

35. Mota, L.; Toledo, R.; Machado, F. A. L.; Holanda, J. N. F.; Vargas, H.; Faria, R. T., Jr. Appl. Clay Sci. 2008, 42, 168-174. doi:10.1016/j.clay.2008.01.010

36. Rosencwaig, A.; Gersho, A. J. Appl. Phys. 1976, 47, 64-69. doi:10.1063/1.322296

37. Faraji, N.; Mat Yunus, W. M.; Kharazmi, A.; Saion, E.; Behzad, K. Int. J. Thermophys. 2014, 35, 53-61. doi:10.1007/s10765-013-1551-7

\section{License and Terms}

This is an Open Access article under the terms of the Creative Commons Attribution License (http://creativecommons.org/licenses/by/2.0), which permits unrestricted use, distribution, and reproduction in any medium, provided the original work is properly cited.

The license is subject to the Beilstein Journal of Nanotechnology terms and conditions: (http://www.beilstein-journals.org/bjnano)

The definitive version of this article is the electronic one which can be found at: $\underline{\text { doi: } 10.3762 / \text { bjnano.6.55 }}$ 